\title{
Individual differences, type of identification response, and practice in absolute identification of pitch
}

\author{
ANTE FULGOSI, ZVONIMIR KNEZOVIĆ, and PREDRAG ZAREVSKI \\ Filozofski fakultet, Zagreb, Yugoslavia
}

\begin{abstract}
Sixteen tones of the same loudness but of different frequencies (80 to 4,400 $\mathrm{Hz}$ ) were presented 100 times each for absolute identification by 10 subjects divided into two experimental groups (Groups A and B). Group A was composed of subjects with "good" identification ability (preexperimental median transmission $=2.75$ bits), and Group B, of subjects with "poor" identification ability (median $=2.29$ bits). Individual and group transmission indices (Fulgosi, Knezović, \& Zarevski, 1983, 1984) for the second half of the present experiment were compared, and a difference in favor of the two group indices appeared in both experimental groups. Two indices of the group identification performance (the indirect based on the dominant responses, and the direct based on group decisions) were larger than the median of the individual identification performance (21\% and $24 \%$ in Group A and $24 \%$ and $29 \%$ in Group B, respectively). These results show that, even for "good" identifiers of pitch, group indices carry substantially more information than individual ones. Both groups also showed a further substantial increase in the amount of transmitted information during the present experiment.
\end{abstract}

In experiments in which absolute identification of stimuli (e.g., tones differing in pitch) is investigated, individual differences usually are neglected or are treated as unsystematic factors. Random selection of subjects is thought to be a correct procedure for distributing evenly such differences in experimental groups on a chance basis and to allow for them. However, individual differences in identification ability can also be introduced into the investigation of identification performance as systematic independent variables. This was done in the present experiment for several reasons.

In two recently published investigations in which individual identification performance indices were compared with group identification performance indices (Fulgosi, Knezović, \& Zarevski, 1983, 1984), several groups of subjects participated in experiments having the same identification task (identification of pitch of pure tones) under identical or highly similar conditions. In this way, it was possible to collect a larger than usual number of individual indices for the amount of transmitted information. Analysis of these data disclosed the existence of substantial differences among the subjects who participated in the identification experiments. The range of the amount of transmitted information in the 20 subjects who participated was from 2.14 to 2.97 bits in the second half of the experiments, in which the feedback information that had been given by the experimenter in the first ("training") half was abolished. In

The authors' mailing address is: Odsjek za psihologiju, Filozofski fakultet, 41000 Zagreb, Yugoslavia. terms of the number of identified categories, these values corresponded to a range of 4.4 to 7.9 categories.

Such large differences may influence the results of experiments in which different independent variables (such as channel capacity, group vs. individual identification performance, etc.) are investigated.

Thus, for example, in the two experiments in which two different types of group identification responses (the dominant response and the response based on the group agreement and decision) were compared, the experimental groups differed in individual identification ability (Fulgosi et al., 1983, 1984).

For these reasons, it seems important to treat individual identification differences as independent variables and to compare the identification performance of subject groups comprising "good" and "poor" identifiers, respectively.

The present experiment was performed with this intention. Since our results in the earlier two experiments seem to corroborate our hypothesis that identification performance is under a strong influence of random factors that operate in subjects during identification and lower their identification performance, we were interested in investigating the influence of such factors in "good" and "poor" identifiers. Such comparisons could be made using the group identification paradigm that had been used in the earlier experiments (Fulgosi et al., 1983, 1984).

On the basis of previous results for the identification of the pitch of pure tones (Fulgosi et al., 1983, 1984), two groups of subjects differing in identification ability 
were formed. The subjects in both groups were exposed to the same tasks that had been used in the earlier experiments: first, to identify, individually, each tone presented, and after that, to reach a group agreement about the identification response that should be given to the experimenter. It is important to note that all subjects in the present experiment had had the same amount of practice in the previous experiments in which they had participated.

\section{METHOD}

\section{Subjects and Groups}

Two groups were formed on the basis of earlier identification results. Group A comprised the five subjects who had yielded the best identification results (measured in bits or in categories), and Group B comprised the five subjects who had performed the worst in the earlier experiments.

All subjects had normal hearing.

\section{Apparatus}

An RC-type generator (Type MA 3604) connected to five Koss earphones generated tones having the same intensity but differing in pitch.

\section{Stimuli}

The following 16 tones were presented to the subjects in each groups for absolute identification: $80,120,160,220,300,400$, $500,700,1000,1500,1800,2400,3000,3400,4000$, and $4400 \mathrm{~Hz}$.

Tones were selected on the basis of a graph of loudness of tones of different frequencies and represent a set of tones of approximately the same loudness (Licklider, 1950).

\section{Procedure}

The experiment was conducted in a sound-attenuating room. Stimuli were presented to both groups in the same random order. Each stimulus was presented for $4 \mathrm{sec}$. The interstimulus interval was $8 \mathrm{sec}$. During the experiment, each tone was presented to the respective group 100 times-5 times in the 20 segments of the experiment.

In the first 10 segments of the experiment (the first half), the subjects were given the feedback information (the correct identification response for just presented stimulus) after each identification response. In the second 10 segments (the second half of the experiment), no feedback was given.

The subjects were told that their task was to identify each tone with the proper number (from 1 to 16 ), where 1 was used for identification of the lowest $(80-\mathrm{Hz})$ tone.

The subjects worked individually. After they had entered their individual identification response for the just-presented tone in their individual protocols, they announced their responses to other members of the group and discussed the differences, reached an agreement about the identification response that they would give as a group to the experimenter, and gave this group identification response to the experimenter.

In all other respects (the order of the announcement of individual responses and the order of the announcement of the group identification responses to the experimenter), the procedure was identical to that in the previous experiments (Fulgosi et al., 1984).

The experiment lasted 5 consecutive days. On each day, four segments of the total experiment were carried out, for a total of 320 stimuli presented. After the first two segments, the subjects were allowed to pause for $5 \mathrm{~min}$.

Before each experimental session, all tones were presented from the lowest to the highest by the experimenter, who also gave the correct identification number for each one. Before the first session, the subjects were given a short training period, comprising 32 presentations of stimuli in random order.
To keep the motivation of the subjects high, after each session, the subjects were informed of the number of correct identifications in the previous session.

\section{RESULTS}

From the individual identification responses in the second half of the experiment, individual transmission indices were calculated, and the median (C) of the five indices for each experimental group was determined. In addition, for each experimental group, the informational value of the dominant responses (Fulgosi et al., 1983) and the informational value of the group responses (based on group consultations and decisions) (Fulgosi et al., 1984) were calculated.

In Table 1, the median values of the amount of information transmitted by individual responses before $\left(C_{1}\right)$ and after $\left(C_{2}\right)$ the experiment for Group $A$ and Group B are shown, along with the informational values of the dominant (D) and group (G) identification responses in the same groups.

In Table 2, the respective number of identified categories for the values in Table 1 are shown.

The increase in the amount of transmitted information in both groups in the case of the group identification indices (the dominant responses and responses based on group agreement and decisions) compared with the median of individual identification responses, expressed as percentages of bits and the number of corresponding identified categories, is shown in Table 3.

\section{DISCUSSION}

The identification performances of the two groups (Groups A and B) expressed by individual, as well as by group, indices in terms of bits or number of identified categories are quite differ-

Table 1

Transmitted Information (in Bits)

\begin{tabular}{cccc}
\hline $\begin{array}{c}\text { Response } \\
\text { Type }\end{array}$ & Group A & Group B & {$[(\mathrm{A}-\mathrm{B}) / \mathrm{B}] \%$} \\
\hline C $_{1}$ & 2.75 & 2.29 & 20.0 \\
C $_{2}$ & 3.30 & 2.68 & 23.0 \\
D & 3.58 & 3.00 & 19.3 \\
G & 3.61 & 3.05 & 18.4 \\
\hline
\end{tabular}

Note $-C_{1}=$ median of individual transmission indices before the present experiment; $C_{2}=$ median of individual transmission indices in present experiment; $D=$ dominant response of the group; $G=$ group decision.

Table 2

Transmitted Information (Identified Categories)

\begin{tabular}{cccc}
\hline $\begin{array}{c}\text { Response } \\
\text { Type }\end{array}$ & Group A & Group B & [(A-B)/B]\% \\
\hline $\mathrm{C}_{1}$ & 6.8 & 4.9 & 38.8 \\
$\mathrm{C}_{2}$ & 9.8 & 6.4 & 53.4 \\
$\mathrm{D}$ & 11.9 & 8.0 & 49.4 \\
$\mathrm{G}$ & 12.2 & 8.3 & 47.4 \\
\hline
\end{tabular}

Note-See Table 1 for definitions of $C_{1}, C_{2}, D$, and $G$. 
Table 3

Differences in Number of Identified Categories (in Percent)

\begin{tabular}{cccc}
\hline Group & $\left(\mathrm{D}-\mathrm{C}_{2}\right) / \mathrm{C}_{2}$ & $\left(\mathrm{G}-\mathrm{C}_{2}\right) / \mathrm{C}_{2}$ & $(\mathrm{G}-\mathrm{D}) / \mathrm{D}$ \\
\hline A & 21.3 & 23.8 & 2.1 \\
B & 24.5 & 28.8 & 3.5 \\
\hline
\end{tabular}

Note-See Table 1 for definitions of $C_{2}, D$, and $G$.

ent (Table 1). The individual indices in Group A and Group B did not overlap after the experiment, which makes the differences between the two groups highly significant $(p<.001)$. The range of individual transmission indices in Group $A$ in the second half of the present experiment was from 2.99 bits ( 8.0 categories) to 3.34 bits (10.1 categories). The range of individual transmission indices in Group B was from 2.32 bits (5.0 categories) to 2.81 bits ( 7.0 categories). The indices did not overlap even before the present experiment.

The difference between the two groups is largest in the case of individual transmission indices. The median of Group $A$ is $23 \%$ greater than the median of Group B, when both are expressed in bits, and 53\% greater when expressed in terms of the number of categories.

The percentage difference between the group identification indices (D and $G$ ) in the two groups is smaller. The difference is $19 \%$ in the case of the dominant responses of the two groups and $18 \%$ in the case of the group decision responses (expressed in bits), and $49 \%$ and $47 \%$, respectively, when expressed as the number of identified categories.

From these results, it is obvious that the group identification performance was more helpful for Group B than for Group A (more helpful to "poor" identifiers than to "good" identifiers).

Information transmission indices in Tables 1 and 2 show that the group identification performance, represented by the dominant or by the group responses, is superior to the individual identification performance expressed by the medians in both experimental groups (see also Table 3). Group transmission indices carry substantially larger amounts of information than do individual ones. It should be noted that the group performance in the case of Group A is very high for this kind of stimulus (12 identified categories). Such identification performance is much higher than the median of individual performance in the same group ( 9.8 categories) and is larger than the best individual transmission index in that group (10 identified categories).

The identification performance of Group B is almost four categories below the group performance of Group A. It is also below the median of the individual indices of Group A. In fact, the performance of Group B as a whole (expressed by the group transmission index, G) is comparable only to the performance of the worst individual in Group A (eight identified categories).

The fact that the group identification performance (indices D and G) in Group A is substantially better than that for individuals shows that, even in the "good" identifiers, random factors are influencing and lowering performance on the identifi- cation of pitch of pure tones and that even their identification performance can be improved when they function as a group (Fulgosi et al., 1983, 1984).

Comparison of the medians of individual transmission indices at the beginning and at the end of the experiment $\left(C_{1}\right.$ and $\left.C_{2}\right)$ in each group shows that both groups improved their identification of pitch during the present experiment. The individual improvement in Group A, expressed by the number of identified categories, is $46 \%$-larger than the comparable improvement in Group B $(31 \%)$-which shows not only that the individual differences persist after identification practice and training, but that they can even be larger after such practice (see also Table 1). Practice in identifying pure tones in an absolute paradigm seems to be more effective when coupled with higher individual identification ability (see also Fulgosi \& Žaja, 1975).

The difference between the two indices of group identification performance (the dominant, or indirect, and the direct indices, based on group consultations and decisions; Fulgosi et al., $1984)$ is quite small $(2.1 \%$ and $3.5 \%$ in Group A and Group B, respectively) and in favor of the second index. Such a difference is much smaller than the difference obtained earlier between these two indices (Fulgosi et al., 1984), when it was almost $15 \%$ and in favor of the index based on group decisions.

The difference between these two indices in the previous and the present investigations could be attributed to the difference in the amount of practice that subjects participating in the previous and the present experiments were allowed. It seems that, for the more practiced subjects, group consultations are not much help. For this reason, it seems that the best strategy for such groups is to derive the group identification response according to the majority rule. Such a dominant response to each stimulus could be derived quickly and automatically by a simple program, which makes the dominant response a very feasible and convenient index of group identification performance in both experimental and practical situations.

\section{REFERENCES}

Fulgosi, A., Knezović, Z., \& Zarevski, P. (1983). Amount of information transmitted in absolute judgments of pitch calculated according to the majority rule. Bulletin of the Psychonomic Society, 21, 193-194.

Fulgosi, A., Knezović, Z., \& Zarevsior, P. (1984). Group decisions and amount of transmitted information in absolute identification and pitch. Bulletin of the Psychonomic Society, 12, 203-204.

Fulaosi, A., \& Ž̃AJA, B. (1975). Information transmission of 3.1 bits in absolute identification of auditory pitch. Bulletin of the Psychonomic Society, 6, 379-380.

Lickider, J. C. R. (1950). Basic correlates of the auditory stimulus. In S. S. Stevens (Ed.), Handbook of experimental psychology. New York: Wiley.

(Manuscript received for publication February 2, 1984.) 